\title{
A novel device to improve robustness of end plate beam- column connections
}

DOI:

10.1016/j.istruc.2020.10.055

\section{Document Version}

Accepted author manuscript

Link to publication record in Manchester Research Explorer

\section{Citation for published version (APA):}

Shaheen, M., Foster, A., \& Cunningham, L. (2020). A novel device to improve robustness of end plate beamcolumn connections. Structures, 28, 2415-2423. https://doi.org/10.1016/j.istruc.2020.10.055

\section{Published in:}

Structures

\section{Citing this paper}

Please note that where the full-text provided on Manchester Research Explorer is the Author Accepted Manuscript or Proof version this may differ from the final Published version. If citing, it is advised that you check and use the publisher's definitive version.

\section{General rights}

Copyright and moral rights for the publications made accessible in the Research Explorer are retained by the authors and/or other copyright owners and it is a condition of accessing publications that users recognise and abide by the legal requirements associated with these rights.

\section{Takedown policy}

If you believe that this document breaches copyright please refer to the University of Manchester's Takedown Procedures [http://man.ac.uk/04Y6Bo] or contact uml.scholarlycommunications@manchester.ac.uk providing relevant details, so we can investigate your claim.

\section{OPEN ACCESS}




\title{
A novel device to improve robustness of end plate beam-column connections
}

\author{
Mohamed A. Shaheen ${ }^{\mathrm{a}, *}$, Andrew S. J. Foster ${ }^{\mathrm{a}, *}$, Lee S. Cunningham ${ }^{\mathrm{a}}$ \\ ${ }^{a}$ School of Mechanical, Aerospace and Civil Engineering, The University of Manchester, Manchester, UK
}

\begin{abstract}
Achieving a robust connection is a challenging task for design engineers since the connection's strength is inseparably linked to its ductility. This paper presents a novel approach that separates designing bolted connections for strength from designing for ductility. By inserting a steel sleeve with a designated length, thickness and wall curvature between the end plate and the washer, the load path between the end plate and the bolts can be interrupted, promoting a more ductile response. End plate connections with various sleeve geometries are numerically investigated using a validated FE model to prove the concept of the proposed method. The proposed system substantially enhances the rotational capacity up to 2.92 times that of the standard connection. An elastic response consistent with standard connections is maintained indicating that the proposed system is compatible with existing codified elastic design approaches without modification.
\end{abstract}

Keywords: End plate connection; Robustness; Rotation capacity; Ductility; Moment connections

\footnotetext{
${ }^{*}$ Corresponding author

Email addresses: m.shaheen@manchester.ac.uk (Mohamed A. Shaheen), andrew.s.j.foster@manchester.ac.uk (Andrew S. J. Foster) 


\section{Introduction}

This study proposes a novel method to increase the robustness of end plate connections by improving the contribution of the bolts to the rotation capacity. In this paper robustness refers to the ability of a structure to withstand an accidental load without being damaged to an extent disproportionate to the original cause [? ]. GSA [? ] and ASCE 41 [14] demonstrate that the rotational capacity of steel connection is considered fundamental in mitigating progressive collapse. The load path shown in Fig. 1 reveals that the commonly adopted methods to improve ductility are either to change the stiffness of the beam, or the stiffness of the end plate. However, the rotational capacity of the connection is mainly controlled by the least ductile elements in the load path which are the bolts $[1,2]$. The end plate connection is commonly analysed and designed using an equivalent T-stub [3], in which the bolts are the boundary conditions. The higher the bolt elongation, the higher the rotational capacity that can be achieved [4]. However, the most common bolts in engineering practice

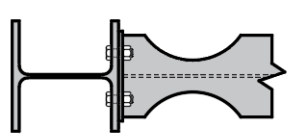

RBS: cut out parts in the beam's flanges.

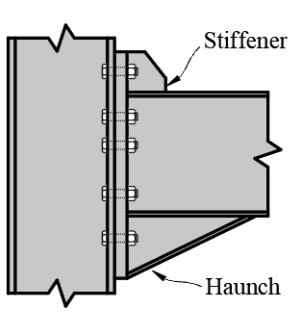

Haunched connection with stiffener

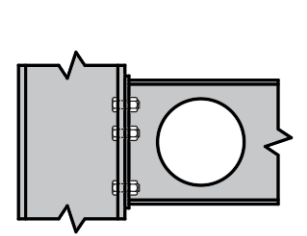

RWS: cut out parts in the beam's web.

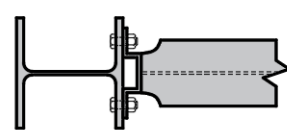

Bolted channel connection

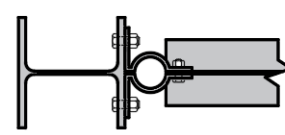

Bolted cylindrical connection

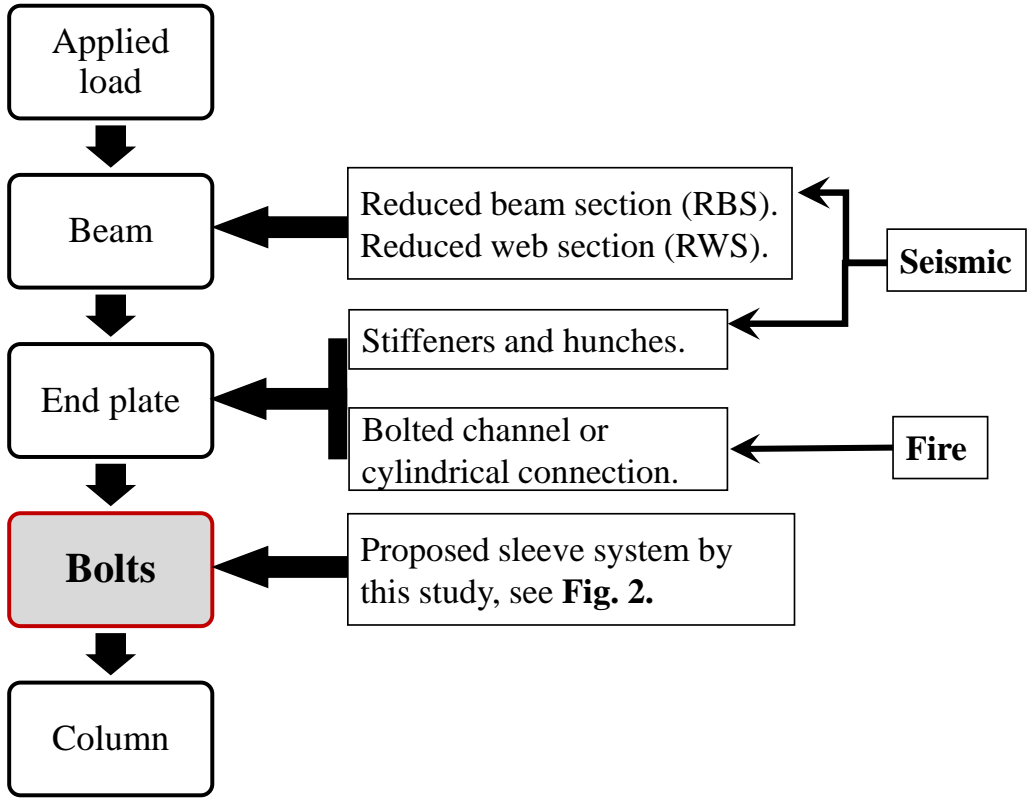

Figure 1: Various methods to increase the ductility of connections. 
are frequently manufactured from high strength steel grades of 8.8 and 10.9 [5] which achieve their ultimate strength at a strain of approximately 0.05 followed by a sudden fracture; by contrast mild steel can achieve a strain of 0.2 without failure. Add to this the small length of the bolt, the contribution of the bolt to rotational capacity due to its elongation is generally minimal when compared with the end plate.

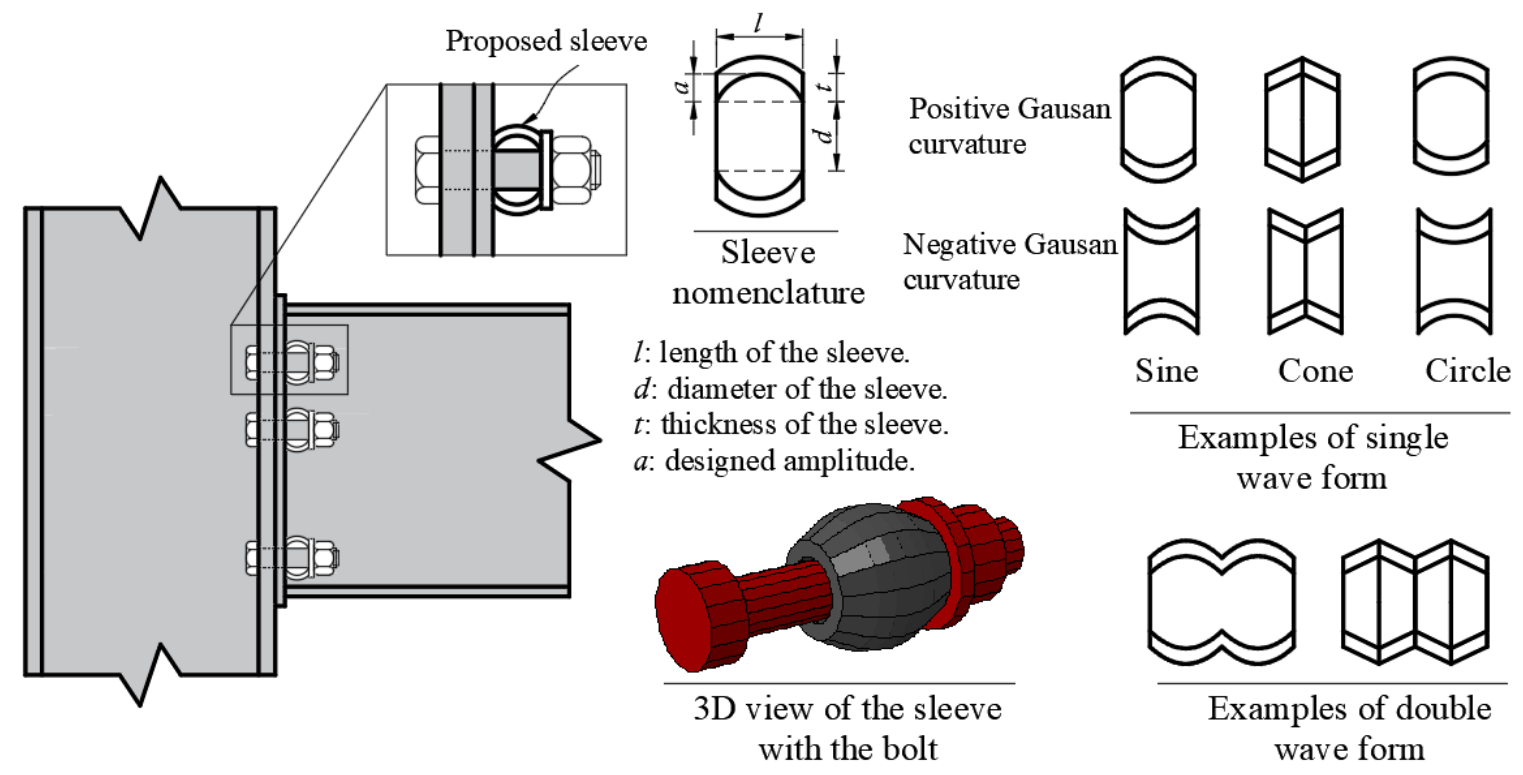

Figure 2: Proposed connection with the sleeve.

Fig. 2 schematically illustrates the proposed system. A sleeve with designated dimensions including length, thickness and wall curvature is inserted between the end plate and the washer. The sleeve is a shell of revolution that resists the applied load by a combination of membrane and bending stress, with the latter becoming more significant as the ratio between the sleeve thickness and radius of curvature is increased [6]. A curvature in the sleeve wall is introduced to promote failure by bending rather than instantaneous buckling. This curvature is defined based on the amplitude at the mid-length of the sleeve and the corresponding geometrical equation of the wave form. Examples of these are shown in Fig. 2. Positive and negative Gaussian curvature are applicable for the same wave form, however, the latter 
requires a washer with very specific dimensions as the outer radius of the sleeve can be larger than the washer radius after introducing the amplitude. Furthermore, the bearing between the sleeve with negative Gaussian curvature and the washer can result in high internal forces in the washer which may require a non-standard thick washer. Therefore, only the sleeve with positive Gaussian curvature is considered in this study.

With respect to Fig. 1, there are three common methods to improve the robustness of end plate steel connections [? ] by mobilising the plastic rotation from connection zone to a predefined location in the beam: strengthening the connection, reducing the beam section (RBS) and reducing the web section (RWS) [7]. These methods can be applied for retrofitting connections as well as in the design of new structures. Retrofit using the first two methods requires damaging parts of the concrete slab. Thus, these methods are usually expensive in terms of time, cost and maintenance. In the proposed sleeve method, the retrofitting process is much simpler requiring only loosening the steel bolts and inserting the sleeve between the end plate and the washer. In the case of damage under extreme loading, the proposed system could reduce repair costs, as the damage would be localised to the sleeve rather than the steel beam.

\section{Scope of the study}

To provide increased ductility, bending deformation must develop in the sleeve before the failure of any connection components. To achieve this, the ultimate capacity of the sleeve should be lower than the force in the bolt at failure. Fig. 3 illustrates the elastic and ultimate design axial force of the sleeve considering various failure modes. If bolt necking is the controlling failure mode, this provides a brittle connection response as opposed to end plate failure. The sleeve should be designed so that $(1)$ its axial elastic strength $\left(F_{\mathrm{s}, \mathrm{el}}\right)$ 
is higher than the code-prescribed bolt strength in order to provide consistent behaviour with the standard connection within the elastic range and $(2)$ its ultimate capacity $\left(F_{\mathrm{s}, \mathrm{u}}\right)$ is less than the bolt ultimate capacity to allow the sleeve to deform plastically before the bolt failure. These can be represented mathematically as:

$$
\begin{gathered}
F_{\mathrm{s}, \mathrm{el}}=\pi \cdot d_{\mathrm{avr}} \cdot t \cdot \sigma_{\mathrm{s}, \mathrm{el}} \geq F_{\mathrm{b}, \mathrm{c}} \\
F_{\mathrm{s}, \mathrm{u}}=\pi \cdot d_{\mathrm{avr}} \cdot t \cdot \sigma_{\mathrm{s}, \mathrm{u}}<F_{\mathrm{b}, \mathrm{u}}
\end{gathered}
$$

where: $d_{\mathrm{avr}}$ is the average diameter of a perfect sleeve $(=d+t) ; d$ is the inner sleeve end diameter; $t$ is the sleeve wall thickness; $\sigma_{\mathrm{s}, \mathrm{el}}$ and $\sigma_{\mathrm{s}, \mathrm{u}}$ are the yield and ultimate strength of the sleeve material; $F_{\mathrm{b}, \mathrm{c}}$ is the bolt capacity based on the Eurocode 3 part 1.8 recommendation $\left(=0.9 \sigma_{\mathrm{b}, \mathrm{u}} A_{\mathrm{s}} / \gamma_{\mathrm{M} 2}\right) ; \sigma_{\mathrm{b}, \mathrm{u}}$ is the ultimate strength of the bolt material; $A_{\mathrm{s}}$ is the bolt stressed area and $\gamma_{\mathrm{M} 2}$ is the partial safety factor; and $F_{\mathrm{b}, \mathrm{u}}$ is the ultimate capacity of the $\operatorname{bolt}\left(=\sigma_{\mathrm{b}, \mathrm{u}} A_{\mathrm{s}}\right)$.

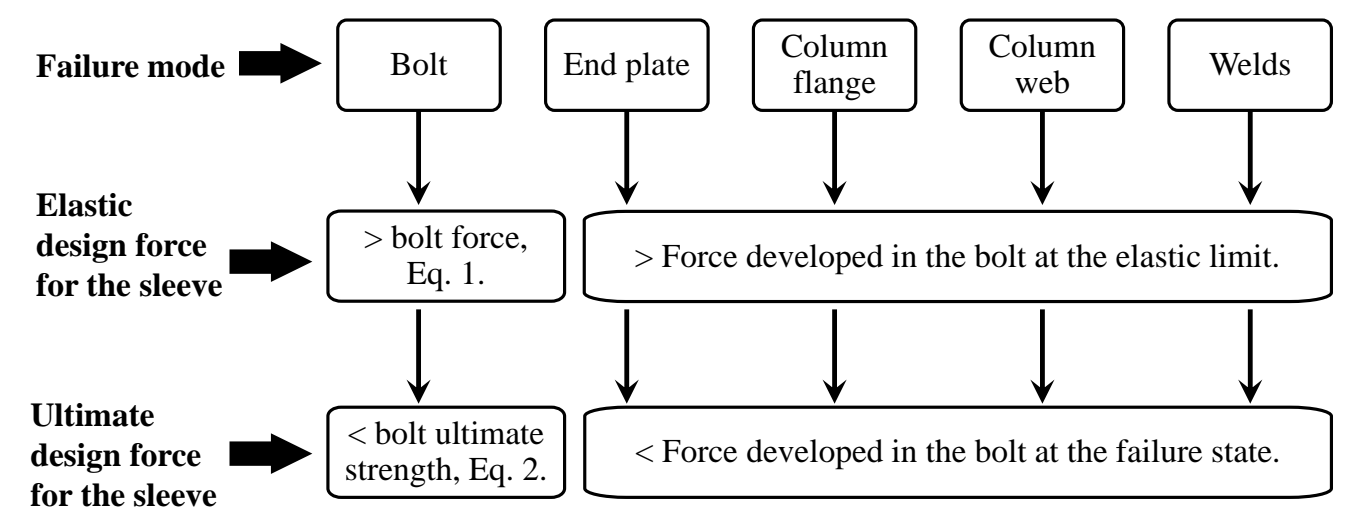

Figure 3: Elastic and ultimate design force for the sleeve corresponding to various failure modes.

The aims of the present work are twofold. First, to prove the concept that the proposed sleeve system can increase the rotational capacity of the connection without affecting its 
elastic behaviour nor its capacity. Second, to conduct a parametric study of a sleeve with a single sinusoidal positive Gaussian curvature to give an insight into the effect of sleeve length and the amplitude value on the connection behaviour. To these ends, a beam-end plate connection is numerically investigated with various sleeve geometries. This study focuses on connections with thick end plates, such that the failure is controlled by the bolt necking, which frequently provides the least ductile connection response. The analysis is carried out using a finite element (FE) model validated against experimental test data from the literature.

\section{FE development}

A numerical model of the connection shown in Fig. 4a is developed using ABAQUS/Standard [8] featuring eight-node linear brick elements with reduced integration (C3D8R), except for the loading plate which is assigned as a rigid body. A fine mesh is adopted in regions of high stress localisation such as the bolt and the end plate. Surface-to-surface interaction with small-sliding formulation and friction coefficient of 0.2 is selected to model tangential behaviour between contact surfaces that may be separated or experience relative slip during the analysis (e.g. the end plate and column flange or the bolt head and plate). The normal behaviour is modelled using a hard contact interaction, which constrains the nodes on one surface to penetrate the other surface. A mesh convergence study was conducted to define the optimum mesh size and the final results are illustrated in Fig. 4b.

A constitutive model based on that of EC3: part 1.2 for carbon steel is used. Yield $\left(F_{\mathrm{y}}=\right.$ $356 \mathrm{MPa})$ and ultimate $\left(F_{\mathrm{u}}=502 \mathrm{MPa}\right)$ stress are defined based on tensile tests carried out

on coupon specimens [9]. For high strength steel, the nominal material properties of bolt grade 8.8 is used $\left(F_{\mathrm{y}}=640 \mathrm{MPa}\right.$ and $\left.F_{\mathrm{u}}=800 \mathrm{MPa}\right)$, with the ultimate strain limited to 


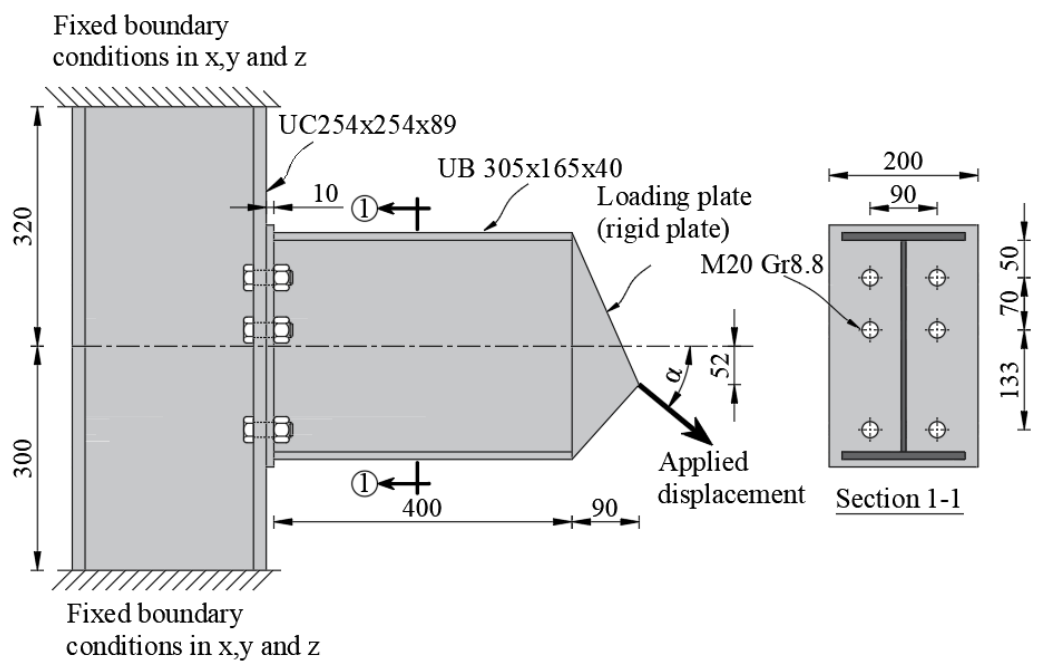

(a) Geometry of the specimen.

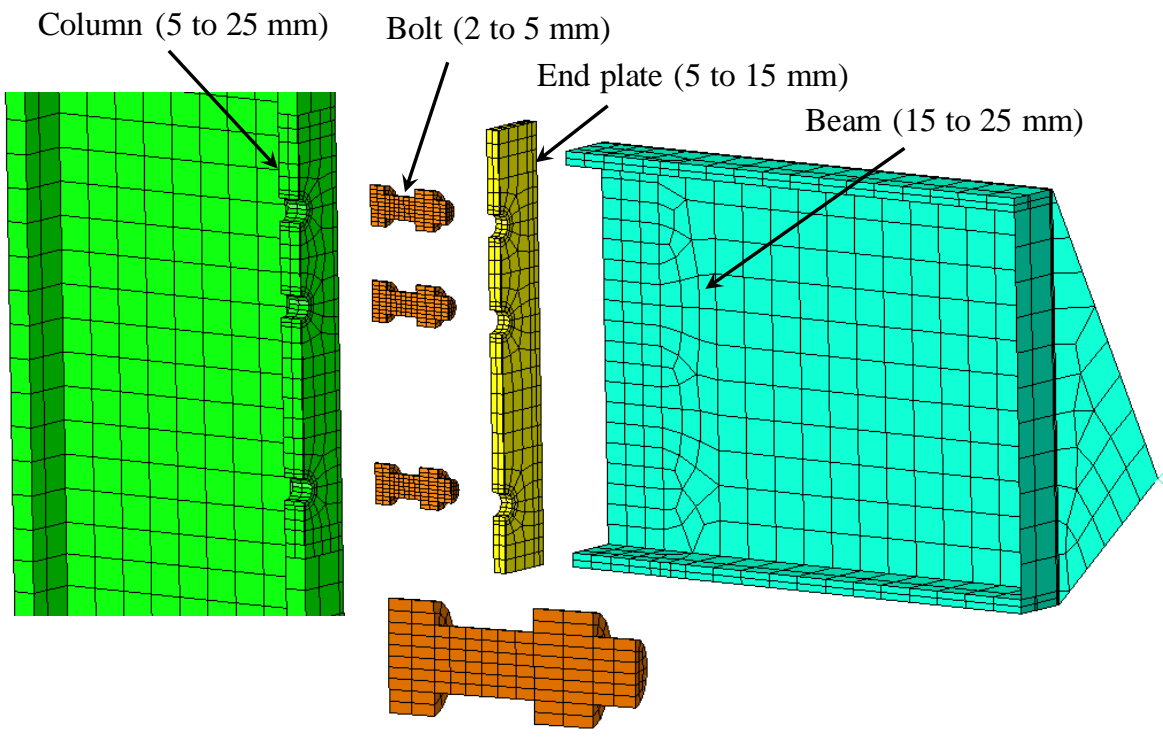

(b) Mesh topology and element size.

Figure 4: Geometry and discretisation of FE model (section cut at centre line of the bolt.)

0.05. Fig. ?? shows the adopted stress-strain curves for the end plate and the bolts. Ductile damage models featured in ABAQUS are used to account for material damage and fracture of the end plate and bolts. Damage to the column and the beam is not considered as this was not observed in published tests [9]. A complete description of the ductile damage requires damage initiation and damage evolution to be defined. Damage initiation is represented by 


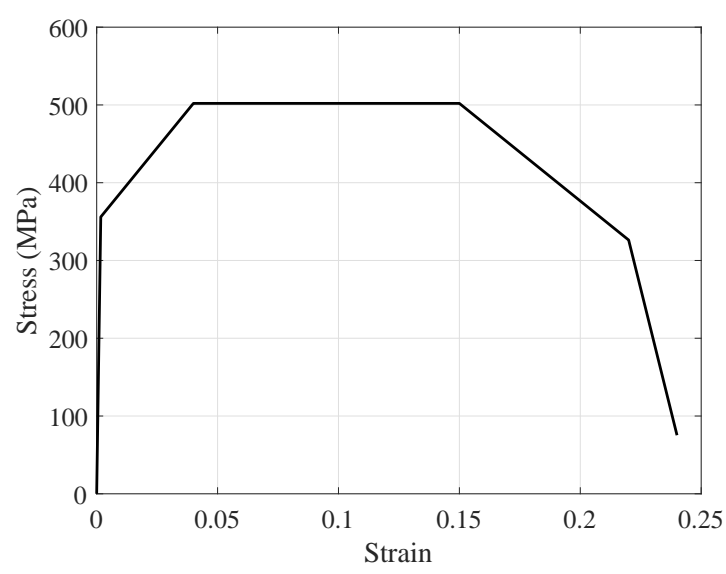

(a) Stress-strain curve for the end plate.

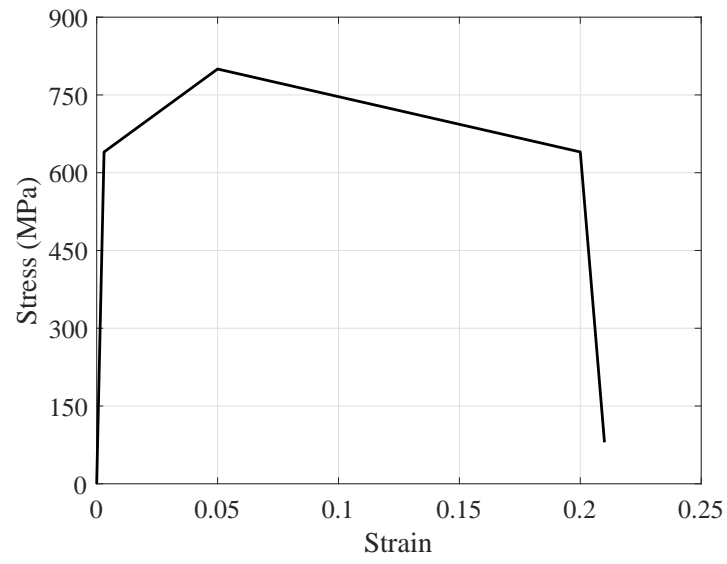

(b) Stress-strain curve for the bolt.

Figure 5: Adopted stress-strain curves.

the equivalent plastic strain at the onset of damage $\bar{\varepsilon}_{0}^{p l}$, where the value of $\bar{\varepsilon}_{0}^{p l}$ is defined as the true plastic strain corresponding to the ultimate stress. In the absence of coupon tests, the damage evolution variable $D$ is defined by trial and error, varying the plastic displacement $\bar{u}^{p l}$ until the post-peak behaviour is captured [10]. The damage parameters are defined following Pavlovic et al [11] and Shaheen et al. [12], with the lowest $D$ value considered during the analysis being 0.9 to avoid sudden drop in stress at the material point, which can cause dynamic instability and convergence problems.

\subsection{Validation}

The FE model in this study is validated against the specimens tested at ambient temperature by $\mathrm{Yu}$ et al. on flush end plate connections [9], see Fig. 4a. The applied force is inclined by an angle $\alpha$ with respect to the beam's axis to produce different combinations of shear and tying force. Due to symmetry, only half of the connection is modelled, with symmetric boundary conditions assigned at the plane of symmetry, which passes through the beam's web. The bolt diameter was modelled based on the effective stress area rather than the full diameter. The thread part of the bolt is not modelled in this study, thus the bolt stripping 
failure mode is not applicable [? ].

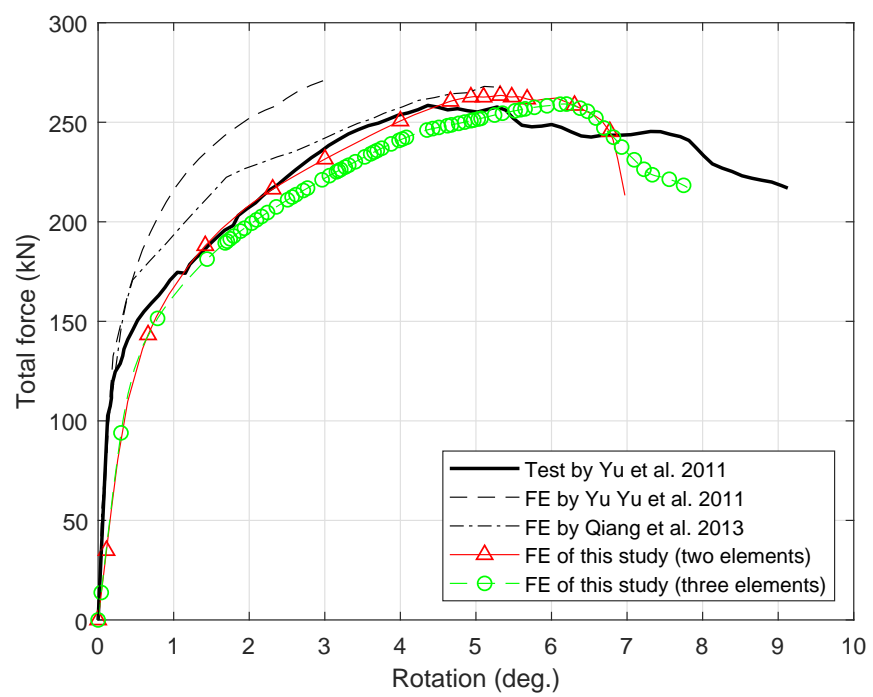

(a) Force-rotation comparison between FE and experimental test.

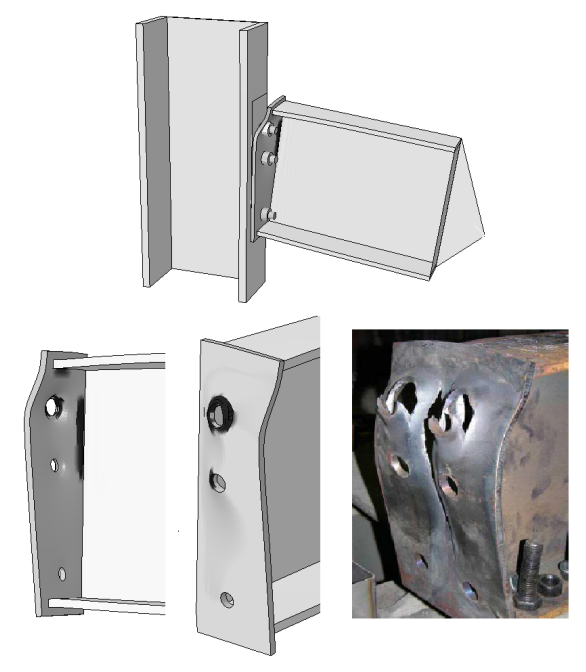

(b) Comparison of simulated and experimental connection [9] failure modes.

Figure 6: FE model validation.

Fig. 5a depicts a comparison of the total force-rotation behaviour for the FE and experimental test. A mesh sensitivity study using two and three elements across the end plate and the column flange is considered. It is clear that both mesh densities record similar response, thus two elements are considered to reduce the computational time. FE simulations carried out by $\mathrm{Yu}$ et al. [9] and Qiang et al. [13] are also plotted for comparison, but it should be noted that they do not model material damage. It is clear from Figs. 5a that the FE simulations presented in this study capture the connection behaviour more accurately, particularly the post-peak response and are on the safe side of the experimental data. More significantly, the FE methodology developed in this paper can accurately predict the failure mode of the connection (Fig. 5b), unlike in previous studies $[9,13]$. It is noted that the FE method developed in the present study depicts a different initial stiffness compared to previous studies $[9,13]$. In Yue et al., the bolt was simulated with a $20 \mathrm{~mm}$ diameter cross section while the bolt strength was modified by 0.81 to give the same ultimate tensile resistance observed 
in the tests. Furthermore, the column was implicitly modelled, with only column flange contact with the end plate being considered in their FE model. In Qiang et al., the bolt diameter of $20 \mathrm{~mm}$ was also used combined with a pretension force which was absent in the experimental tests. In this study the effective stress area of the bolt is considered, the exact material properties are defined and the column is explicitly modelled. The initial stiffness of this study is therefore slightly lower, which can be attributed to adopting the effective stress area approach and the flexibility provided by the column.

It should be noted that whilst the parametric study that follows considers bolted connections with a thick end plate such that bolt necking is the dominant failure mode, the FE is validated against a connection that features plate failure to account for the interactions between the sleeve and the end plate, including the possibility of altering the failure mode from bolt necking to plate failure.

\section{The proposed sleeve system}

The same connection configuration as in the validated model is re-analysed using the proposed sleeve system. A sleeve thickness of $5 \mathrm{~mm}$ is defined based on Eq. (1) and (2) with grade S355 steel. It should be pointed out that the sleeve material is modelled using a bilinear stress-strain relation, without considering material damage due to the absence of coupon tests. Furthermore, the load is applied in the vertical direction rather than inclined with the beam axis. To avoid the end plate failure mode, its thickness is increased to $15 \mathrm{~mm}$. In practice, the sleeve should be inserted between the end plate and the washer for every bolt in the connection. However, due to the nature of the applied load considered in this study, the bolt adjacent to the compression flange is modelled without the sleeve to reduce the computational effort. 
Four different sleeve configurations are considered: (i) single sine wave (SSW); (ii) single cone wave (SCW); (iii) double sine wave (DSW); and (iv) double cone wave (DCW). The single wave forms are analysed with sleeve length-to-bolt diameter $(l / d)$ ratios of 1.0 and 1.5 while ratios of 1.5 and 2.0 are considered for the double wave forms. Furthermore, three wave amplitudes of $1.0 \mathrm{~mm}, 3.0 \mathrm{~mm}$ and $6.0 \mathrm{~mm}$ are considered for each sleeve. Specimens are identified using the system in Fig. 6 .

Fig. 7 shows the plastic strain for the sleeved connections with different sleeve lengths and amplitudes, corresponding to the connection's capacity. It is clear that the sleeve with a high amplitude of $6 \mathrm{~mm}$ experiences severe plastic deformation, eventually crushing between the end plate and the washer, prior to the connection developing its ultimate capacity. Sleeves with a small amplitude of $1.0 \mathrm{~mm}$ exhibit minor deformation in the sleeve and thus the plastic strain is concentrated in the bolt shank. It should be noted that the ultimate failure mode for connections with and without sleeves is bolt necking, indicating that whilst the sleeve can delay the failure to a high rotation, ultimate failure eventually takes place in the bolt.

Fig. 8 depicts the force-rotation behaviour of sleeved connections with single and double wave forms. The behaviour of standard connections and the Eurocode 3 part 1.8 capacity

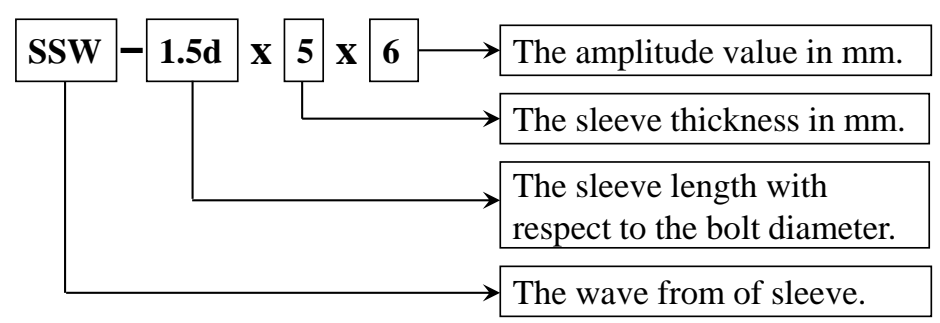

Figure 7: Specimen identifier. 


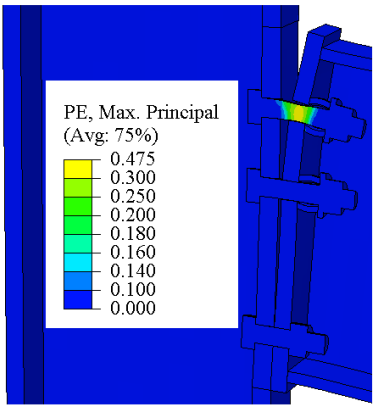

SSW-1dx $5 \times 1$

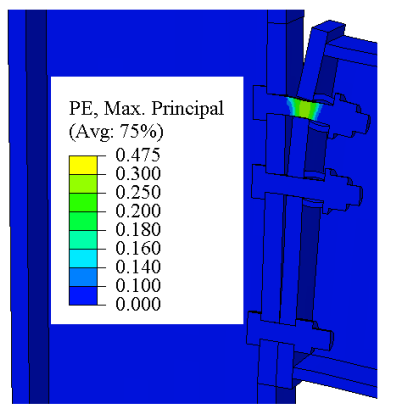

SCW-1dx $5 \times 1$

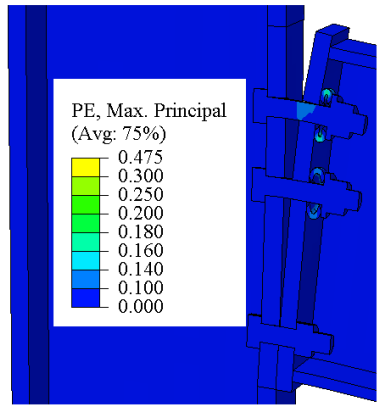

SSW- $1 \mathrm{~d} \times 5 \times 6$

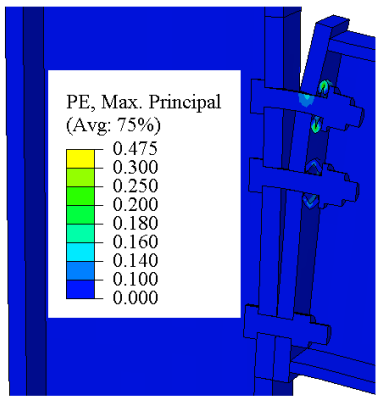

SCW-1dx5x6

(a) Single wave forms $l / d=1.0$

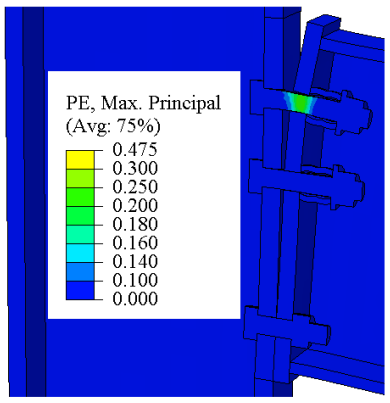

DSW- $1.5 \mathrm{~d} \times 5 \times 1$

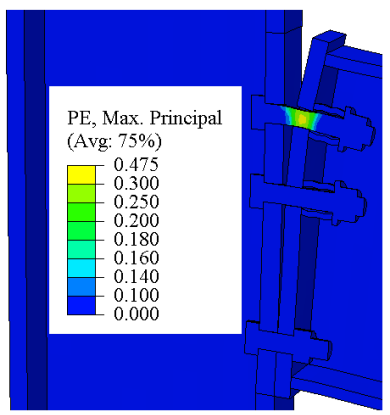

DCW-1.5 $\mathrm{d} \times 5 \times 1$

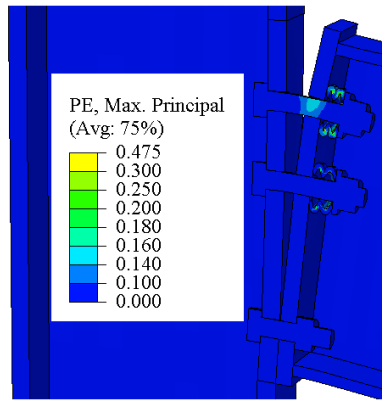

DSW-1.5dx5x6

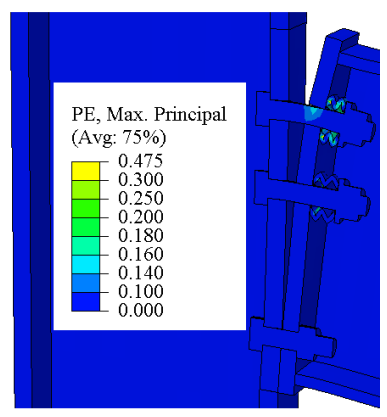

DCW-1.5dx5x6 (b) Double wave forms $l / d=1.5$.

Figure 8: Plot of plastic strain for single and double wave sleeves, corresponding to the connection's capacity, (section cut at centre of the bolts).

are also plotted for comparison. The ratio between the ultimate rotation of the sleeved connections to the standard connection is presented in the legend between the parentheses. The ultimate rotation is defined when the applied force on the connection degrades by $20 \%$ from the ultimate capacity [14]. With reference to the figures, the ductility of sleeved connections is significantly higher than the standard configuration for all amplitude values. Sleeves with small amplitude values up to $3 \mathrm{~mm}$ exhibit the same behaviour as standard configurations, but with a substantially more ductile response, ranging between 1.54 and 2.44 times the standard configuration; increasing the amplitude value further increases the rotational capacity. Furthermore, the initial stiffness of the sleeved connections are consistent with the standard configuration up to the Eurocode 3 part 1.8 limit, indicating the proposed sleeve system is compatible with Eurocode 3 in the elastic range without modification. Ultimate 


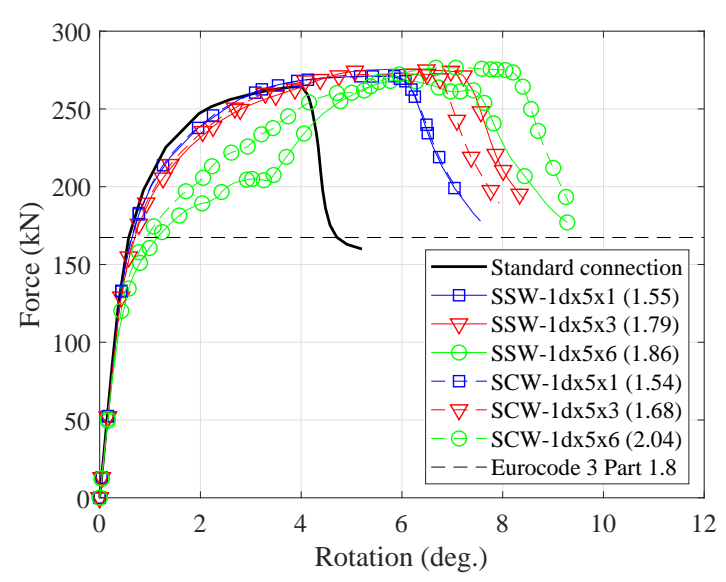

(a) SSW and SCW sleeves with $l / d=1.0$

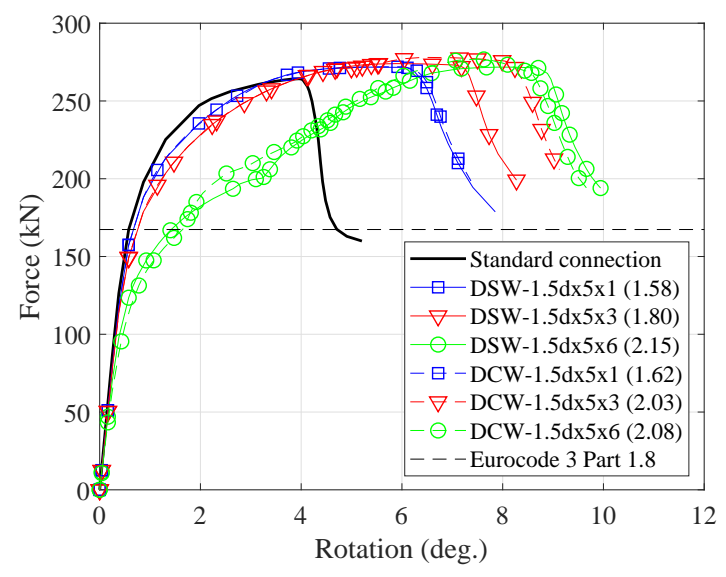

(c) DSW and DCW sleeves with $l / d=1.5$

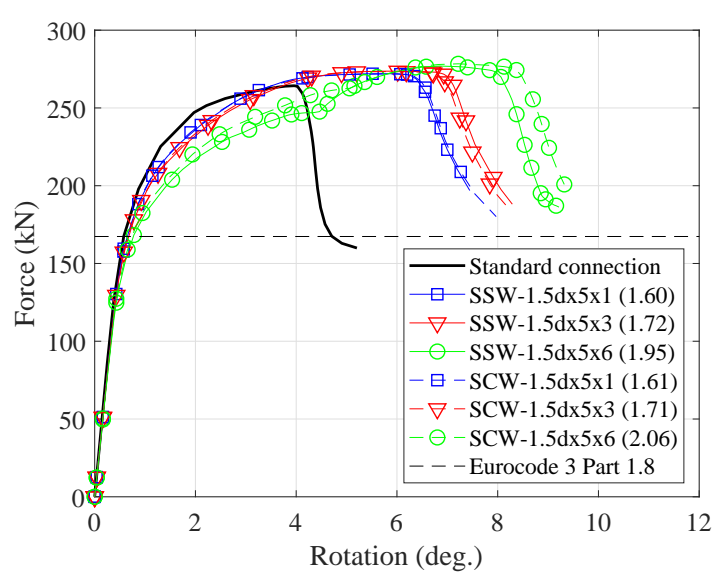

(b) SSW and SCW sleeves with $l / d=1.5$

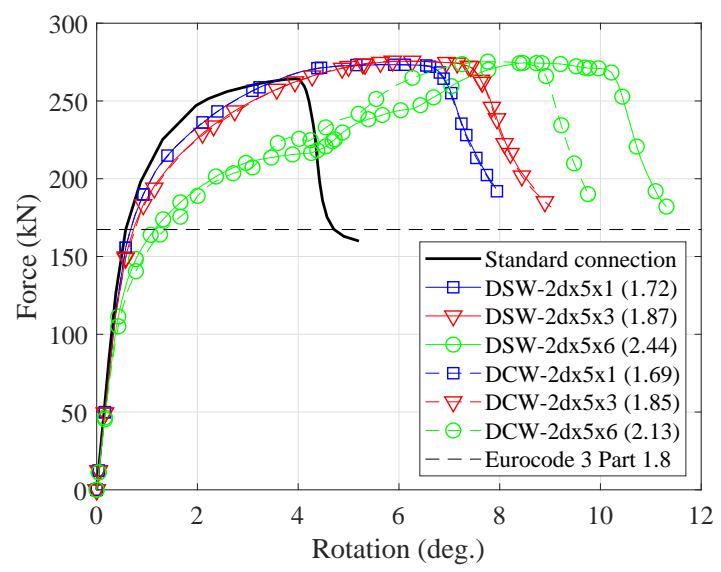

(d) DSW and DCW sleeves with $l / d=2.0$

Figure 9: Behaviour of the connection with single and double wave sleeves.

capacity is also increased as the sleeve enables the lower bolts to more effectively contribute to resisting the applied load, eliminating the unzipping failure mode regularly associated with thick end plates. Ultimately, all the connections fail by bolt necking irrespective of the sleeve configuration and characteristics.

\section{Behaviour of connections with the SSW sleeve}

The previous section shows that the sleeve with strength defined by Eqs. 1 and 2 has a rotational capacity depending on the wave form, amplitude value and $l / d$ ratio. To limit the 
number of FE simulations required, this paper will limit its focus to the SSW sleeve configuration to determine the optimal amplitude for each $l / d$ ratio. A sine wave is considered as it is frequently used to define the initial imperfection profile of shells for buckling analysis [15].

Fig. 9 depicts the effect of amplitude values on rotational capacity normalised by that of the standard connection $\left(R / R_{\text {std }}\right)$. The relative rotational capacity increases with the amplitude up to a specific value followed by slight decrease. The higher the $l / d$ ratio the higher the rotational capacity that can be achieved; however, the rotational capacity is more sensitive to the amplitude value with high $l / d$ ratios. For instance, increasing the amplitude value from $7.0 \mathrm{~mm}$ to $7.5 \mathrm{~mm}$ resulted in a $34 \%$ increase in rotational capacity.
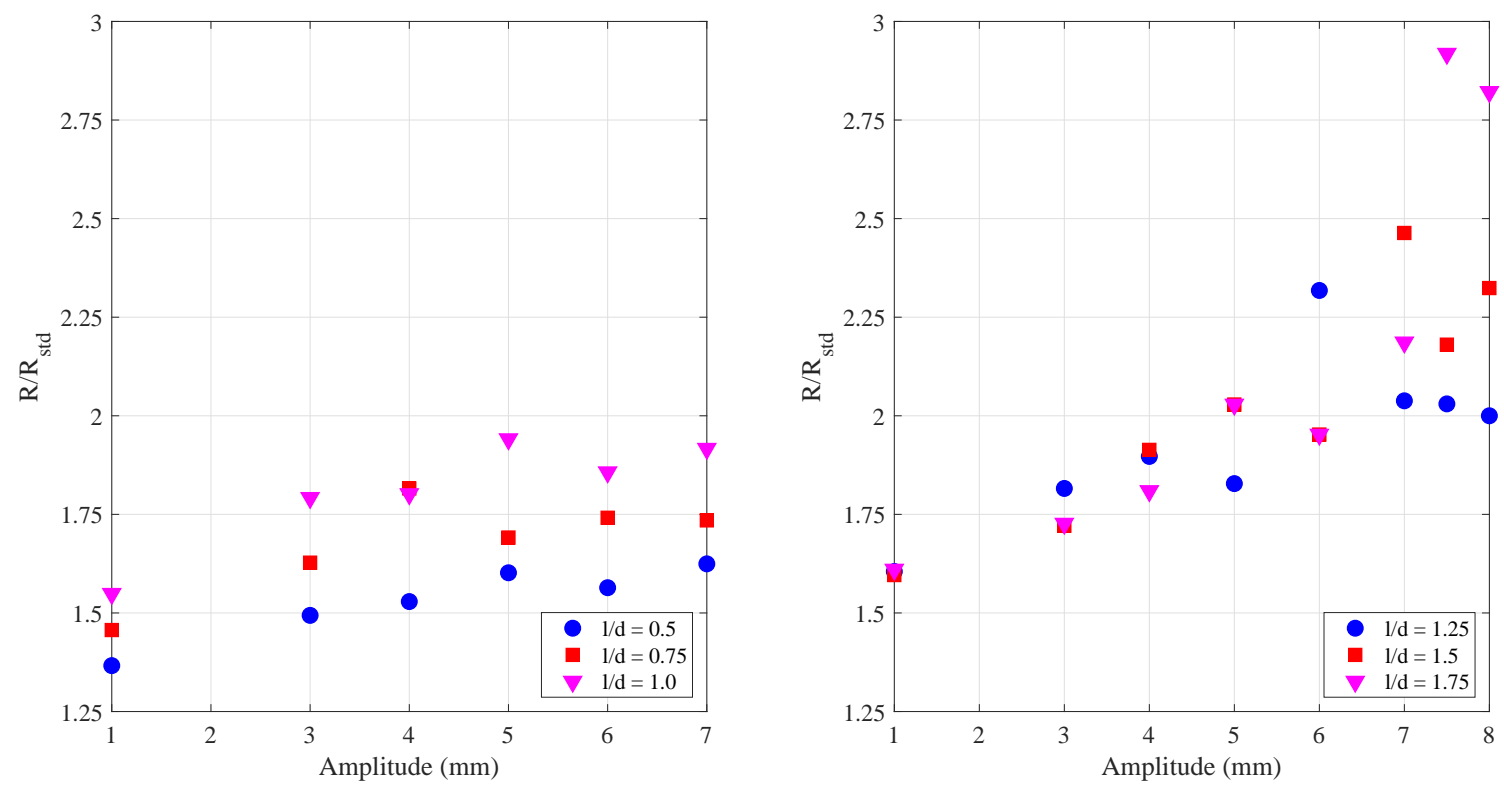

Figure 10: Effect of amplitude on the behaviour of connections with SSW sleeves.

Fig. 10 compares the axial deformation in the bolt and the sleeve when various amplitude values are used with an $l / d$ ratio of 1.25 . There are four distinct combinations of behaviour, depending upon the sleeve amplitude. When a small amplitude value of $1 \mathrm{~mm}$ is used (Fig. 


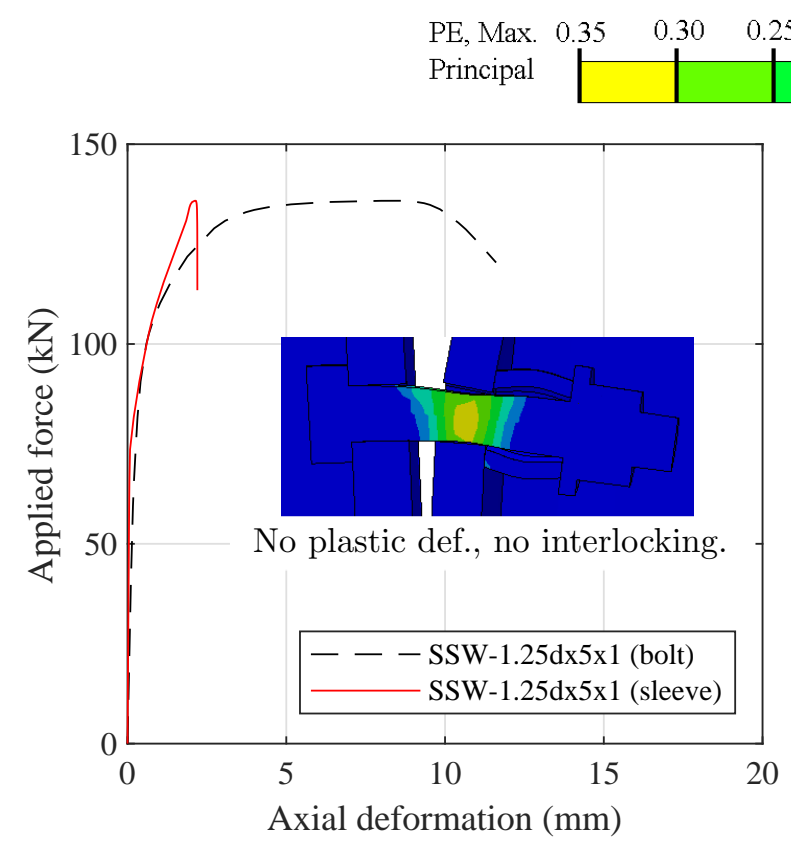

(a)

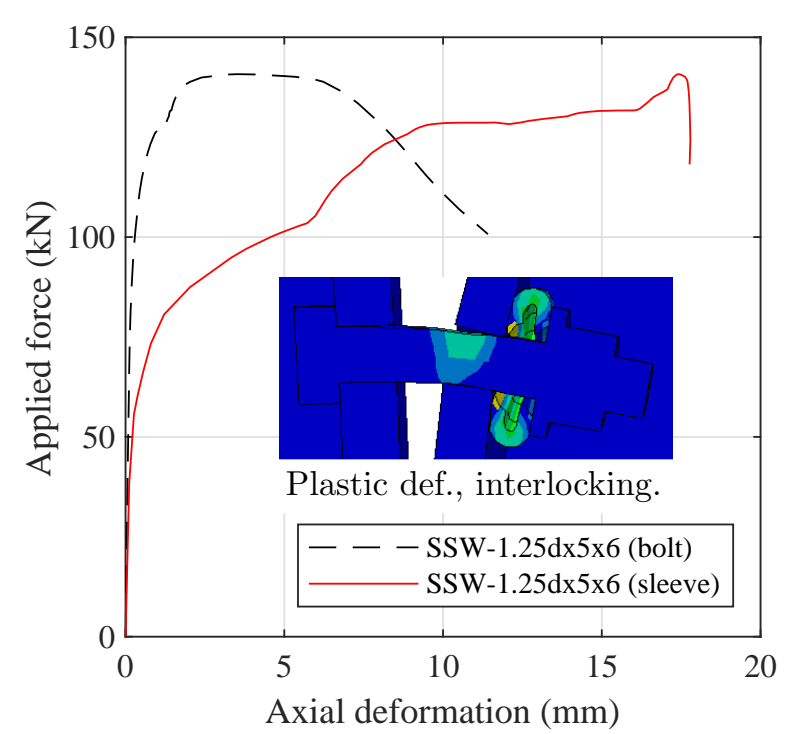

(c)

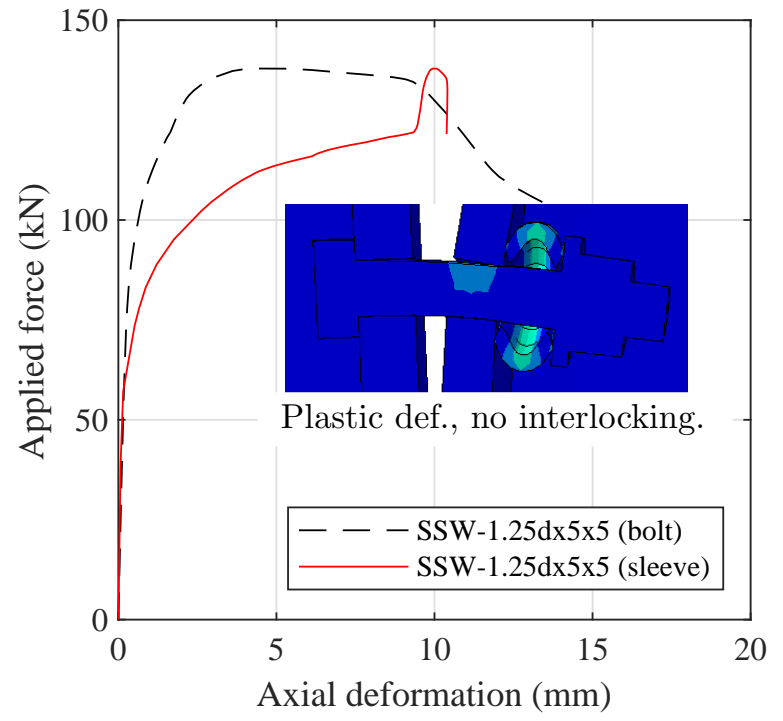

(b)

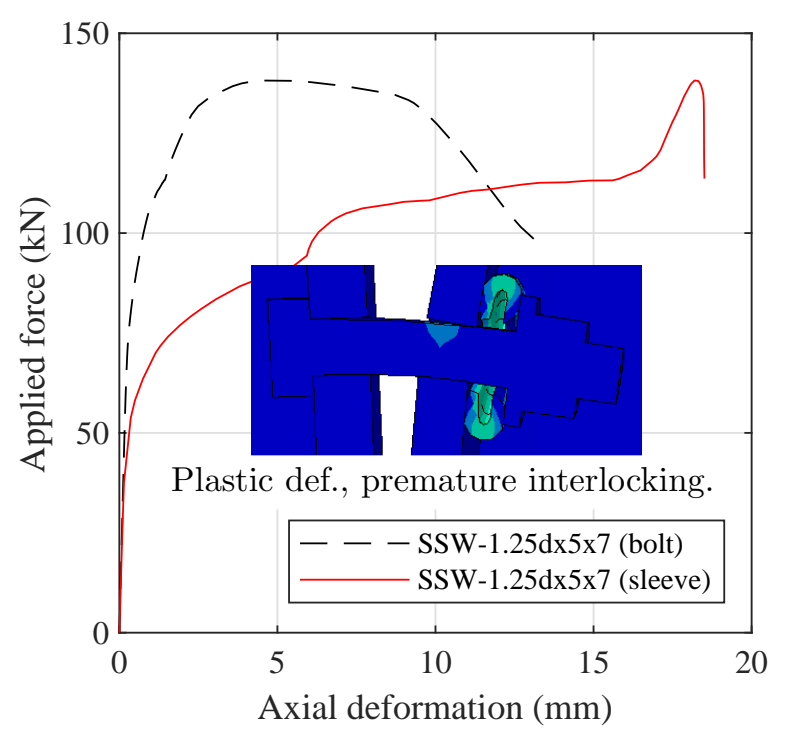

(d)

Figure 11: Axial deformation and plastic strain of bolt and sleeve under the applied load.

10a), the sleeve undergoes insufficient deformation causing the bolts to fail without achieving any significant enhancements to ductility. Increasing the amplitude value to $5 \mathrm{~mm}$ reduces 
the bending capacity of the sleeve and thus limited plastic deformation is observed before the bolt failure (Fig. 10b). For amplitudes of $6 \mathrm{~mm}$ and $7 \mathrm{~mm}$ (Fig. 10c and 10d), the sleeves exhibit significant plastic deformation eventually crushing between the end plate and the washer before the bolt failure. For example the axial deformation at $120 \mathrm{kN}$ is $7.5 \mathrm{~mm}$ for a sleeve amplitude of $6 \mathrm{~mm}$ and $17 \mathrm{~mm}$ for an amplitude of $7 \mathrm{~mm}$. The applied force attains the peak value either when the sleeve jams between the washer and the end plate, as for amplitudes of $6 \mathrm{~mm}$ and $7 \mathrm{~mm}$, or when the force in the sleeve exceeds the bolt capacity, providing that the sleeve capacity is higher than the bolt capacity, as for amplitudes of $1 \mathrm{~mm}$ and $5 \mathrm{~mm}$. The optimal amplitude is the threshold value between the amplitude that provides a rigid sleeve and the amplitude that provides a highly flexible sleeve which prematurely interlocks with the end plate and the washer.

\subsection{Optimal amplitude}

Table 1 summaries the optimal amplitude values for SSW sleeves across various $l / d$ ratios for M16 Gr 8.8 and M20 Gr 8.8 bolts, when a thick end plate is used such that failure takes place in the bolt. The sleeve thickness is $5 \mathrm{~mm}$ for M20 $\mathrm{Gr} 8.8$ bolts and $4 \mathrm{~mm}$ for M16 grade 8.8 bolts. It is clear that the optimal amplitude for the SSW sleeves depends on the $l / d$ ratio. Except for sleeves with $l / d$ ratios less than 0.75 , the ratio between the amplitude value and the sleeve length is roughly similar, with an average of 0.225 .

\subsection{Optimal thickness}

The sleeve thickness should be defined based on Eq. 1 and 2. If the thickness of the sleeve is higher than that required, the amplitude value can be increased to reduce the sleeve capacity. Fig. 11 depicts a comparison between different sleeve thickness with the amplitude of the

shown sleeves selected so that the optimal behaviour is achieved. It is clear that the sleeves with different thicknesses provide comparable connection behaviour, however with different 
Table 1: Optimal sleeve amplitude (sleeve material is S355 and bolt grade is 8.8).

\begin{tabular}{|c|c|c|c|c|c|c|}
\hline $\begin{array}{c}\text { Bolt diam., } \\
d(\mathrm{~mm})\end{array}$ & $\begin{array}{c}\text { Sleeve length, } \\
l(\mathrm{~mm})\end{array}$ & $l / d$ & $\begin{array}{c}\text { Optimal } \\
\text { ampl. }(\mathrm{mm})\end{array}$ & $\mathrm{Ampl} . / l$ & $\mathrm{~T} / \mathrm{T}_{\text {std }}$ & $\mathrm{R} / \mathrm{R}_{\text {std }}$ \\
\hline \multirow{5}{*}{20} & 10 & 0.50 & 4.0 & 0.400 & 1.026 & 1.530 \\
\cline { 2 - 7 } & 15 & 0.75 & 4.0 & 0.267 & 1.040 & 1.820 \\
\cline { 2 - 7 } & 20 & 1.00 & 4.5 & 0.225 & 1.049 & 2.000 \\
\cline { 2 - 7 } & 25 & 1.25 & 5.5 & 0.220 & 1.065 & 2.320 \\
\cline { 2 - 7 } & 30 & 1.50 & 7.0 & 0.233 & 1.068 & 2.460 \\
\hline \multirow{4}{*}{16} & 35 & 1.75 & 7.5 & 0.214 & 1.078 & 2.920 \\
\cline { 2 - 7 } & 12 & 0.50 & 3.5 & 0.438 & 1.049 & 1.440 \\
\cline { 2 - 7 } & 16 & 1.00 & 3.5 & 0.219 & 1.018 & 1.620 \\
\cline { 2 - 7 } & 20 & 1.25 & 4.5 & 0.225 & 1.000 & 1.810 \\
\cline { 2 - 7 } & 24 & 1.50 & 5.0 & 0.208 & 1.080 & 1.890 \\
\cline { 2 - 7 } & 28 & 1.75 & 7.0 & 0.250 & 1.030 & 1.620 \\
\hline
\end{tabular}

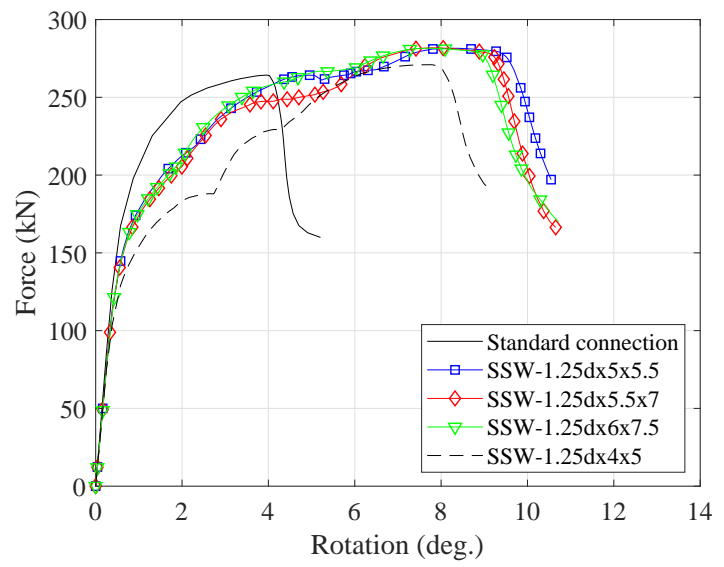

(a) SSW sleeve with $l / d$ ratio $=1.25$.

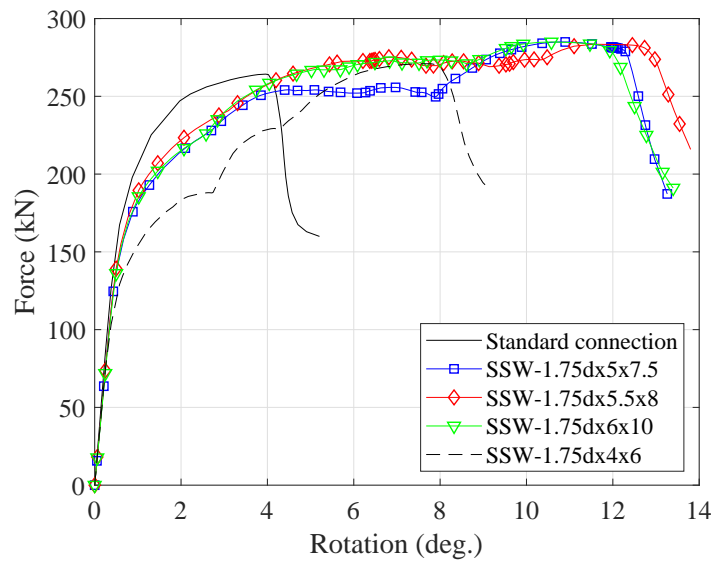

(b) $\mathrm{SSW}$ sleeve with $l / d$ ratio $=1.75$.

Figure 12: Effect of thickness of the sleeve on connection behaviour.

amplitudes, the larger the thickness, the higher the amplitude required to reduce the sleeve bending capacity. On the other hand, a sleeve with a thickness less than the value obtained from Eq. 1 (i.e. $4 \mathrm{~mm}$ ) is plotted on Fig. 11 to illustrate its effect on the connection behaviour. The elastic stiffness and the rotation capacity of the connection are reduced. However, the strength of the connection is not affected as the failure eventually takes place in the bolts. Overall, it is recommended to use the minimum thickness that satisfies Eqs. 1 
and 2 as larger thicknesses consume higher quantities of material without adding any benefit to the connection performance.

\section{Discussion}

In this study, nominal material properties are used for the sleeve. However, the strength of the supplied material is frequently higher than the nominal value. If the sleeve thickness is defined based on the nominal value, its ultimate capacity would be higher than the bolt capacity leading to the bolt failing without developing sufficient plastic deformation in the sleeve. Fig. 12 illustrates the behaviour of two sleeves with different $l / d$ ratios, at their optimal amplitudes, when a high material strength is considered. The higher the material strength, the lower the rotational stiffness of the connection. A feasible solution is to apply stringent control on the sleeve material properties. However, further analysis is required to define the margin for the increase in the material strength and a possible factor of safety.

The connections investigated in the present study are analysed under bending with the absence of axial force in the beam. Thus, no tension is applied to the lower bolts adjacent to the compression flange causing them to act solely under pure shear stress. Typically, in connections subjected to bending and shear, the vertical shear is assumed to be resisted by the bolts adjacent to the compression flange [16]. However, if the axial force in the beam is higher than the plastic capacity of the sleeves, a lever arm is generated from shortening of the sleeves and movement of the end plate away from the column flange. Eventually, bending stress can develop in the bolts which may result in premature failure of the connection attributable to the negligible flexural strength of bolts. One possible solution is to resist the applied shear force by a different system to the bolts (e.g. a seat angle with the flush end plate connection).

The primary objective of this study is to prove the concept of the proposed sleeve device 


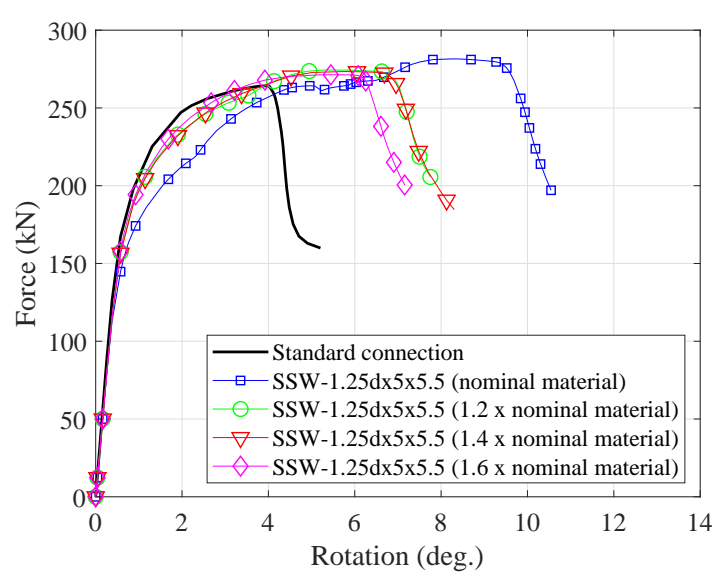

(a) SSW sleeve with $l / d$ ratio $=1.25$.

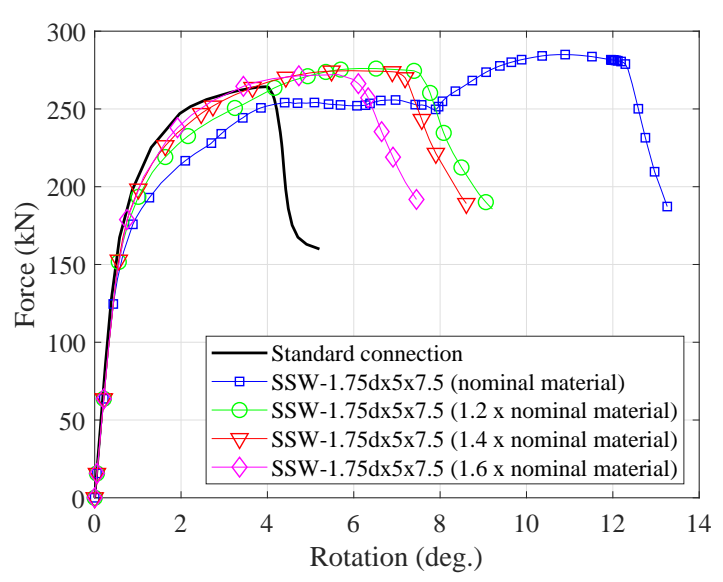

(b) SSW sleeve with $l / d$ ratio $=1.75$.

Figure 13: Effect of sleeve material properties on connection ductility.

leaving various parameters for future investigation including: i) the behaviour of the sleeved connection when additional failure modes such as end plate, web-panel zone and weld cracking, are expected; ii) the effect of bolt pre-loading on the sleeve response; iii) the effect of friction between the sleeve and the steel plates on the sleeve capacity. Subsequent work will include experimental investigations, so that the metallurgical failure modes that can arise from microscopic defects can be taken into account. This will inform the development of analytical models and design methodologies for practical applications.

\section{Conclusion}

This study presents a novel method to enhance the rotational capacity of beam-column end plate connections by improving the contribution of the bolts. The proposed system constitutes a sleeve with designated dimensions including length, thickness and wall curvature that is inserted between the end plate and the washer. Providing that the ultimate capacity of the sleeve is lower than the force in the bolt at failure, the sleeve develops a severe bending deformation before the failure of any connection components. End plate connections with various sleeve geometries are numerically investigated using a validated FE model to prove 
the concept. The analysis shows that the proposed system substantially enhances the rotational capacity of connections, ranging between 1.54 and 2.44 times the standard connection, depending on the wave form and the amplitude value of the sleeve. The sleeved connections depict a consistent elastic response with the standard connections, indicating that the proposed system is compatible with the codified elastic design approach without modification.

A study into behaviour of a sleeved connection with a single sinusoidal positive Gaussian curvature has been carried out. It is shown that for a specific sleeve length, the rotational capacity of sleeved connections depend on the sleeve amplitude value. The optimal amplitude is a threshold value between the amplitude that provides a rigid sleeve and the value that provides a highly flexible sleeve.

In the traditional connection forms previously described (Fig. 1), achievement of the required ductility may necessitate significant iterative design until both strength and ductility requirements are satisfied. However, in the sleeve method presented here, various ductile responses can be achieved without altering connection strength or basic configuration. In the case of existing buildings subject to extreme loads, the proposed system provides a simple and cost effective method of retrofit.

\section{Acknowledgements}

This project is funded by a University of Manchester Dean's Award Scholarship, whose sponsorship is gratefully acknowledged. Dr. Jonathan Gosaye Fida Kaba is duly acknowledged. 


\section{References}

[1] A. S. James and T. L. Roberto, "BOLTED STEEL CONNECTIONS: TESTS ON TSTUB COMPONENTS," Journal of Structural Engineering, vol. 126, no. 1, pp. 91-99, 2000.

[2] L. Simões Da Silva, A. Santiago, and P. Vila Real, "A component model for the behaviour of steel joints at elevated temperatures," Journal of Constructional Steel Research, vol. 57, no. 11, pp. 1169-1195, 2001.

[3] BSI, "BS EN 1993-1-8:2005 - Eurocode 3: Design of steel structures - Part 1-8: Design of joints," British Standards Institution (BSI), London, UK, 2005.

[4] D. Beg, E. Zupančič, and I. Vayas, "On the rotation capacity of moment connections," Journal of Constructional Steel Research, vol. 60, no. 3-5, pp. 601-620, 2004.

[5] BSI, "BS EN ISO 898-1:2013 - Mechanical properties of fasteners made of carbon steel and alloy steel Part 1: Bolts, screws and studs with specified property classes - Coarse thread and fine pitch thread," British Standards Institution (BSI), London, UK, 2013.

[6] A. Zingoni, Shell structures in civil and mechanical engineering, 2nd edition. ICE Publishing, jan 2017.

[7] M. A. Shaheen, K. D. Tsavdaridis, and S. Yamada, "Comprehensive FE Study of the Hysteretic Behaviour of Steel-Concrete Composite and Non-Composite RWS Beam-toColumn Connections," Journal of Structural Engineering, vol. 3, no. 9, pp. 1-13, 2018.

[8] ABAqUS, "Abaqus 6.19," Dassault Systèmes Simulia Corp., Providence, RI, USA, 2019. 
[9] H. Yu, I. W. Burgess, J. B. Davison, and R. J. Plank, "Experimental and Numerical Investigations of the Behavior of Flush End Plate Connections at Elevated Temperatures," Journal of Structural Engineering, vol. 137, no. 1, pp. 80-87, 2011.

[10] M. Seif, J. Main, J. Weigand, T. P. McAllister, and W. Luecke, "Finite element modeling of structural steel component failure at elevated temperatures," Structures, vol. 6, pp. 134-145, 2016.

[11] M. Pavlović, Z. Marković, M. Veljković, and D. Bucrossed D Signevac, "Bolted shear connectors vs. headed studs behaviour in push-out tests," Journal of Constructional Steel Research, vol. 88, pp. 134-149, 2013.

[12] M. A. Shaheen, L. S. Foster, Andrew S.J. Cunningham, and S. Afshan, "A numerical investigation into stripping failure of bolt assemblies at elevated temperatures," Structures.

[13] X. Qiang, F. S. K. Bijlaard, and H. Kolstein, "Post-fire performance of very high strength steel S960," Journal of Constructional Steel Research, vol. 80, pp. 235-242, 2013.

[14] R. Pekelnicky, S. D. Engineers, S. . E. Chris Poland, and N. . D. Engineers, "ASCE 41-13: Seismic evaluation and retrofit rehabilitation of existing buildings," Convention Proceedings of the Structural Engineers Association of California (SEAOC), Santa Fe, New Mexico, USA, 2012.

[15] S. P. Timoshenko and J. M. Gere, Theory of elastic stability, 2nd edition. McGraw-Hill, 1963.

[16] SCI, Publication P398 - Joints in Steel Construction: Moment Resisting Joints to Eurocode 3. The Steel Construction Institute (SCI) \& The British Constructional Steelwork Association (BCSA), UK, 2015. 